\title{
CHARACTERIZATION OF LPCVD AND PECVD SILICON OXYNITRIDE FILMS
}

\author{
F.H.P.M. HABRAKEN \\ Deparment of Atomic and Interface Physics. Utrecht State University, P.O. Box 80.000, \\ 3508 TA Utrecht. The Netherlands
}

Received 13 April 1987; accepted for publication 23 April 1987

\begin{abstract}
The chemical composition and structure of silicon oxynitrides, deposited in low pressure and plasma enhanced chemical vapour deposition processes are discussed. From an extrapolation of the characteristics of plasma grown oxynitrides a model for the deposition of LPCVD material is derived. A main conclusion of this model is that $\mathrm{Si}-\mathrm{Si}$ bonds have a larger tendency to vocur in this material than Si dangling bonds.
\end{abstract}

\section{Introduction}

Investigations of deposited silicon oxynitrides are stimulated by the expectation that the beneficial properties of silicon nitride and silicon oxide for their application in IC technology can be combined in one and the same material. The work is further encouraged by the fact that these silicon oxynitrides can be grown via a simple extension of current LPCVD and PECVD nitride or oxide processes, therefore introduction of these materials is not hindered by major modifications of existing technologies.

This paper deals with the physico-chemical characterization of LPCVD and PECVD silicon oxynitride films and its implications for the growth of the material. Also effects of anneal treatments will be discussed. It will be shown that the use of the high energy ion beam methods Rutherford backscattering spectrometry (RBS), elastic recoil detection (ERD) and nuclear reaction analysis (NRA) is very useful in this field. The information obtained from these techniques is complemented by (Fourier transform) infrared absorption spectroscopy (FTIRAS) to reveal the bonding configurations and by electron spin resonance (ESR) measurements to trace the Si dangling bonds. Since it is believed that hydrogen plays a very important role in the deposition and the performance of the material, emphasis is put on the hydrogen chemistry in the silicon oxynitrides.

In order to develop a model for the deposition of LPCVD oxynitrides, information from anneal experiments of PECVD oxynitrides is used.

0169-4332/87/\$03.50 Elsevier Science Publishers B.V.

(North-Holland Physics Publishing Division) 


\section{Characterization techniques}

An important factor in the characterization studies is the non-destructiveness of the techniques used. It emerged [1-3] that one must be very careful in the interpretation of measured spectra in electron and X-ray excited electron spectroscopies (AES, XPS) because of artifacts due to the electron beam and the sputter ion beam, which is used to remove superficial oxide layers and to obtain depth profiles. For instance, Wurzbach and Grunthaner applied chemical etching in conjunction with XPS to obtain a detailed compositional depth profile of MNOS structures [4].

It appeared that Rutherford backscattering spectrometry (RBS) in combination with channeling was suitable to determine the amounts of silicon, oxygen, nitrogen and chlorine in the silicon (oxy)nitride films [5-7]. By applying channeling with a low exit angle for the detected backscattered ions a depth resolution of $1 \mathrm{~nm}$ appeared possible for very thin nitride films [7]. However, hydrogen cannot be detected using RBS. Total hydrogen concentrations may be determined with a relevant sensitivity using elastic recoil detection (ERD), which is essentially the complementary technique of RBS [8]. This technique yields also accurate values for the amount of $\mathrm{O}$ and $\mathrm{N}$ in the oxynitride films. However in ERD the depth resolution for II is poor. To obtain the depth distribution of $\mathrm{H}$, nuclear reaction analysis (NRA) is commonly used [8,9]. When the reaction ${ }^{1} \mathrm{H}\left({ }^{15} \mathrm{~N}, \alpha \gamma\right){ }^{12} \mathrm{C}$ is used the depth resolution amounts to about $5 \mathrm{~nm}$ in the surface region.

Optical methods are highly rated on the scale of non-destructiveness. Infrared absorption spectroscopy has been used in the study of silicon (oxy)nitride films to reveal the amount of $\mathrm{Si}-\mathrm{H}$ and $\mathrm{N}-\mathrm{H}$ bond concentrations $[5,10-12]$ and to measure the $\mathrm{O} / \mathrm{N}$ ratio in the material. Furthermore, an attempt has been made to gain information about the structure of the material [12]. Ellipsometry is often used to determine the refractive index of the grown material, which is then used to establish the chemical composition. However, especially in the case of plasma grown layers, one must be careful using this procedure since it does not yield unambiguous results.

Electron spin resonance data on deposited silicon oxynitrides are scarce. They are difficult to obtain for (LP)CVD films because films with thicknesses of $\sim 1 \mu \mathrm{m}$ are necessary to obtain sufficient intensity in the spectra. In principle, this method may give information about the neutral dangling bond density of $\mathrm{Si}$ and $\mathrm{N}$ and the microscopic structure of silicon oxynitrides.

\section{Results and discussion}

\subsection{LPCVD silicon oxynitrides}

\subsubsection{Deposition and bulk composition}

In this section results will be discussed which have been obtained in the 

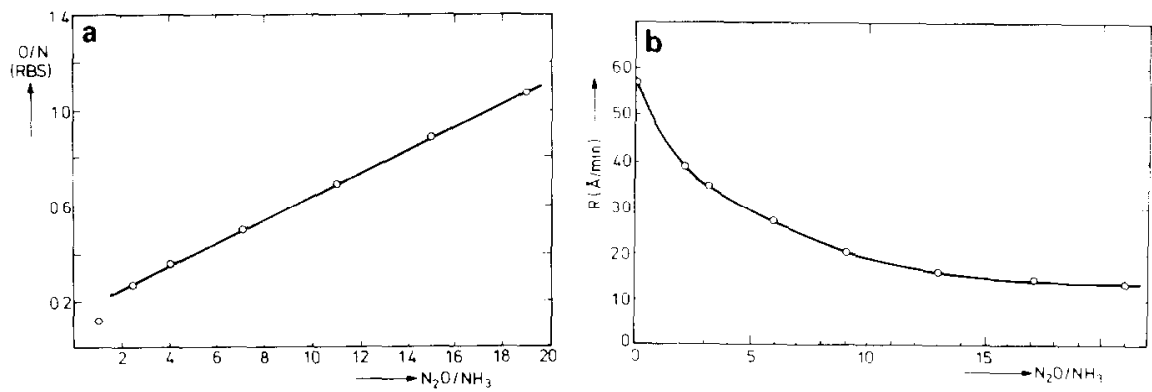

Fig. 1. O/N concentration ratio (a) and growth rate (b) as a function of the $\mathrm{N}_{2} \mathrm{O} / \mathrm{NH}_{3}$ gas phase ratio [15].

study of LPCVD silicon oxynitride films. The films under consideration were grown from $\mathrm{SiH}_{2} \mathrm{Cl}_{2}, \mathrm{NH}_{3}$ and $\mathrm{N}_{2} \mathrm{O}$ at temperatures around $800^{\circ} \mathrm{C}$ and pressures of a few hundred $\mathrm{mT}$ Torr.

Within an accuracy of $5 \%$ stoichiometric $\mathrm{Si}_{3} \mathrm{~N}_{4}$ films can be grown when using a $\mathrm{NH}_{3} / \mathrm{SiH}_{2} \mathrm{Cl}_{2}$ gas flow ratio of 2.5. In these circumstances the grow th rate is about $6 \mathrm{~nm} / \min [6,13]$. The films contain 3 at $\%$ hydrogen [8], which is largely incorporated in $\mathrm{N}-\mathrm{H}$ bonds as is revealed by IR spectroscopy applying multiple internal reflection (MIR) [14] and by ERD of $\mathrm{Si}_{3} \mathrm{~N}_{4}$ deposited from deuterated ammonia [8]. The $\mathrm{Cl}$ content is 0.2 at $\%$ as deduced from RBS measurements [6].

The introduction of $\mathrm{N}_{2} \mathrm{O}$ in the LPCVD reactor results in the incorporation of oxygen in the growing films [15]. Fig. 1a shows that the $\mathrm{O} / \mathrm{N}$ concentration ratio in the oxynitride films increases linearly with the $\mathrm{N}_{2} \mathrm{O} / \mathrm{NH}_{3}$ gas phase ratio, however the $\mathrm{NH}_{3}$ flow has to be strongly reduced in order to incorporate oxygen in the films. Apparently the reactivity of $\mathrm{N}_{2} \mathrm{O}$ towards the growth surface is much lower than that of $\mathrm{NH}_{3}$. At the same time the growth rate decreases with increasing $\mathrm{N}_{2} \mathrm{O} / \mathrm{NH}_{3}$ ratio (fig. 1b). The onset of growth of $\mathrm{Si}_{3} \mathrm{~N}_{4}$ on $\mathrm{Si}$, covered with a native oxide, is delayed [16]. It has been suggested that the native oxide has to be (partly) converted into an oxynitride via reaction with ammonia before the actual deposition can start at an appreciable rate [16]. This indicates that not only the gas phase composition but also the composition of the growth surface is of importance for the deposition rate.

In spite of the decreasing average reactivity of the gas phase molecules which do not contain silicon, and the declining growth rate, no significant amounts of excess silicon have been measured with RBS in the resulting silicon oxynitrides [15]. Excess silicon is defined as the amount of silicon that is in excess of the amount necessary to completely saturate the available $\mathrm{O}$ and $\mathrm{N}$ bonds.

The $\mathrm{Cl}$ concentration in the oxynitrides increases with increasing $\mathrm{O} /(\mathrm{O}+\mathrm{N})$ ratio from 0.2 at $\%$ for the nitride to 0.65 at $\%$ for the oxide (fig. 2). 


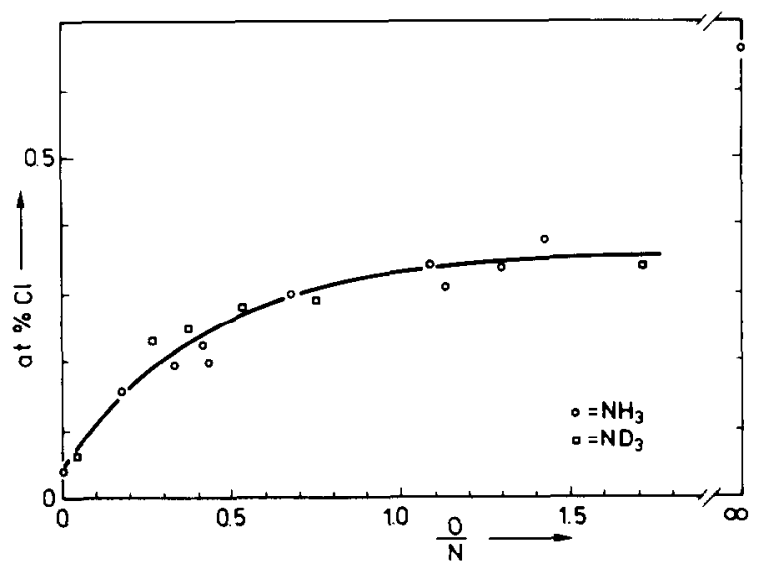

Fig. 2. $\mathrm{Cl}$ concentration in LPCVD oxynitrides as a function of the $\mathrm{N}_{2} \mathrm{O} / \mathrm{NH}_{3}$ gas phase ratio [8].

The bulk $\mathrm{H}$ concentration in LPCVD silicon oxynitrides, as measured using NRA, is given in fig. 3. In the as-deposited films $[\mathrm{H}]$ is independent of the $\mathrm{O} /(\mathrm{O}+\mathrm{N})$ ratio for low oxygen contents. At larger $\mathrm{O} /(\mathrm{O}+\mathrm{N})$ it decreases until at even larger oxygen concentrations it increases again. Annealing at 900 and $1000^{\circ} \mathrm{C}$ in vacuum results in a decrease at all $\mathrm{O} /(\mathrm{O}+\mathrm{N})$, but now a maximum in $[\mathrm{H}]$ occurs at $\mathrm{O} /(\mathrm{O}+\mathrm{N})$ around 0.3 . It appears that around this composition $\mathrm{H}$ in the material is the most stable against heat treatment. To obtain more information about the origin of $\mathrm{H}$, oxynitrides from $\mathrm{SiH}_{2} \mathrm{Cl}_{2}$, $\mathrm{N}_{2} \mathrm{O}$ and $\mathrm{ND}_{3}$ were deposited. The amount of $\mathrm{D}$ incorporated relative to the amount of $\mathrm{N}$ has a maximum around $\mathrm{O} /(\mathrm{O}+\mathrm{N})=0.3$. After annealing this

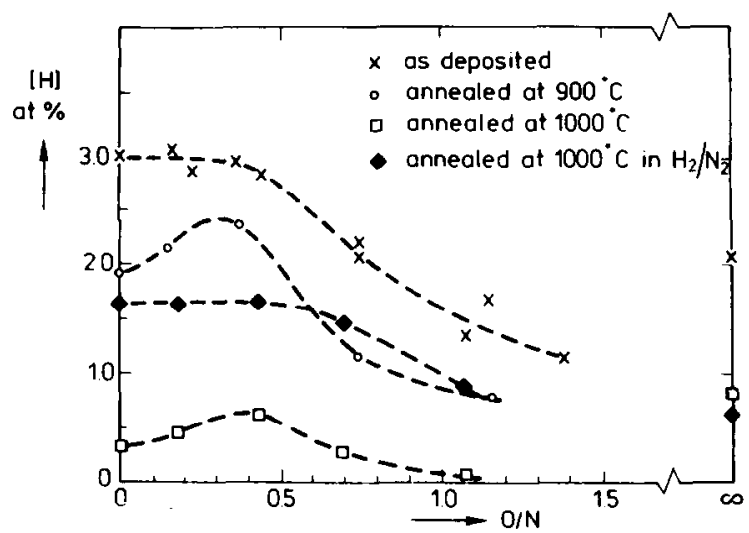

Fig. 3. Bulk $\mathrm{H}$ concentrations in LPCVD oxynitrides as a function of $\mathrm{O} / \mathrm{N}$ after treatments as indicated [8]. 


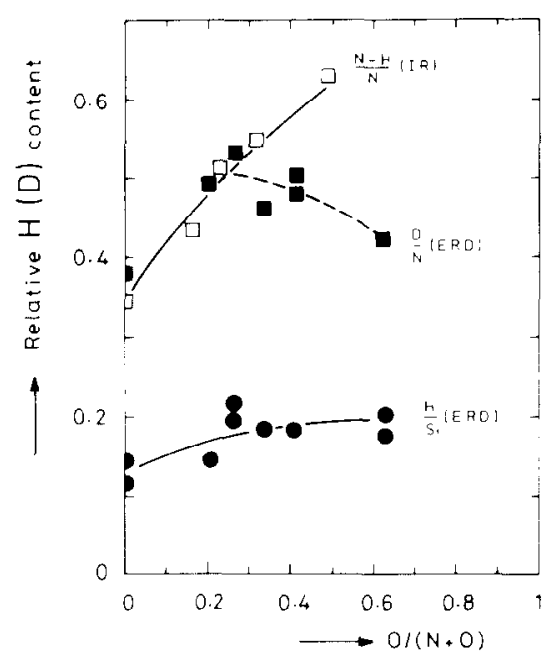

Fig. 4. Amount of $\mathrm{N}-\mathrm{II}$ (IR) and D (ERD) relative to the amount of $\mathrm{N}$ in LPCVD oxyritrides (from refs. $[8,14]$ ).

maximum is more pronounced, indicating that at that composition the deuterium is the most stable in the film. Assuming that no isotope exchange occurs in the gas phase during deposition it was concluded that in the $\mathrm{NH}_{3}$ grown films $\mathrm{H}$ is mainly bonded to $\mathrm{N}$ at not too large $\mathrm{O} /(\mathrm{O}+\mathrm{N})$ ratios [8]. This has been corroborated later by IR measurements by Remmerie [14]. For low $\mathrm{O} /(\mathrm{O}+\mathrm{N})$ there is quantitative agreement between the ERD deuterium data and the MIR IR measurements, but for $\mathrm{O} /(\mathrm{O}+\mathrm{N})>0.3$ deviations occur (fig. 4), i.e. in the IR study more $\mathrm{N}-\mathrm{H}$ bonds are measured than $\mathrm{D}$ in the ERD study.

The $\mathrm{Si}-\mathrm{H}$ bond concentration is below the detection limit of the IR technique. From an ERD analysis of the $\mathrm{ND}_{3}$ deposited oxynitrides it is estimated that the amount of $\mathrm{Si}-\mathrm{H}$ bonds is about 0.2 at\% and increases with increasing oxygen content. It is interesting to note that also in the LPCVD of $\mathrm{SiO}_{x}$ from $\mathrm{SiH}_{4}$ and $\mathrm{N}_{2} \mathrm{O}$ the $\mathrm{H}$ uptake in the growing film increases with increasing oxygen uptake [17]. This is also accompanied by a decrease in growth rate.

There is an indication that around $\mathrm{O} /(\mathrm{O}+\mathrm{N})=0.3$ a small maximum occurs in the $\mathrm{Si}-\mathrm{H}$ bond concentration. However, because of the poor depth resolution of the ERD technique for $\mathrm{H}$, this conclusion cannot be drawn with certainty since in the spectra there is also a contribution of adsorbed $\mathbf{H}$ in water or hydrocarbons. NRA of deuterated material is impeded by a interfering nuclear reaction of ${ }^{15} \mathrm{~N}$ with $\mathrm{D}$.

At low $\mathrm{O} /(\mathrm{O}+\mathrm{N})$ ratios the IR and ERD N-H concentration measurements agree very well. This indicates that isotope exchange in the gas phase 
plays a minor role or, possibly, no role at all in the deposition of the deuterated films. Therefore, we conclude that $\mathrm{N}-\mathrm{H}$ bonds are incorporated via incompletely decomposed $\mathrm{NH}_{3}$ molecules. Despite the decreasing $\mathrm{N}$ concentration in the films or the decreasing $\mathrm{NH}_{3}$ flow in the reactor at increasing $\mathrm{O} /(\mathrm{O}+\mathrm{N})$ the amount of $\mathrm{N}-\mathrm{H}$ is independent of $\mathrm{O} /(\mathrm{O}+\mathrm{N})$, at least for $\mathrm{O} /(\mathrm{O}+\mathrm{N})<0.5$. We conclude that the decomposition of $\mathrm{NH}_{3}$ becomes more difficult in situations where more $\mathrm{O}$ is incorporated. Furthermore the $\mathrm{N}-\mathrm{H}$ bonds become increasingly more stable against annealing for $\mathrm{O} /(\mathrm{O}+\mathrm{N})<0.3$ [8]. These two effects seem interrelated.

Except in a study of Peercy et al. [18], concerning oxynitrides deposited in a APCVD process from $\mathrm{SiH}_{4}, \mathrm{NH}_{3}$ and $\mathrm{O}_{2}$, no indications for $\mathrm{O}-\mathrm{H}$ groups have been found. This is in accordance with the results of a high resolution electron energy loss (HREELS) study of Nishijima et al. [19], who observed a decomposition of $\mathrm{SiOH}$ groups into $\mathrm{Si}-\mathrm{O}-\mathrm{Si}$ and $\mathrm{Si}-\mathrm{H}$ on a $\mathrm{Si}(111)$ surface at temperatures above $\sim 400^{\circ} \mathrm{C}$.

\subsubsection{Interface}

For $\mathrm{O} /(\mathrm{O}+\mathrm{N})>0.3$ the ratio $\mathrm{D} / \mathrm{N}$ in the films decreases with increasing oxygen content [8], whereas the concentration ratio $\mathrm{N}-\mathrm{H} / \mathrm{N}$ as measured with IR increases [14]. This apparent discrepancy between the ERD and the IR results may be found in the assumptions made to derive the relevant physicochemical information. For the ERD data the critical assumption is that no isotope exchange occurs in the gas phase. The interpretation of the IR measurements involves a constant absorption cross section for the $\mathrm{N}-\mathrm{H}$ stretching vibration. However, there is one parameter which is different in the IR and ERD study, i.e. the thickness of the analysed films. The most important conclusion of a recent study of $\mathrm{H}$ profiles in LPCVD silicon oxynitrides is that for $\mathrm{O} /(\mathrm{O}+\mathrm{N})>0.5$ the interfacial region is different from the oxynitride bulk with respect to the binding state of hydrogen [20]. The IR data are obtained from films with a thickness of $80 \mathrm{~nm}$ whereas the films used in the ERD study had a thickness of only 10-20 nm. The annealing behaviour of the $\mathrm{H}$ concentration profiles, the ERD deuterium data and the IR data can be accommodated in one and the same model if it is assumed that at the larger oxygen contents the interfacial region is enriched in $\mathrm{Si}-\mathrm{H}$ and depleted in $\mathrm{N}-\mathrm{H}$ bond concentration compared to the bulk of the silicon oxynitrides. In the absence of direct measurements this inference has to be considered as tentative.

Since (oxy)nitrides may be used as dielectric in MNOS non-volatile memories, the charge trapping behaviour of silicon nitride and especially of the oxide/nitride interface region has been studied in detail. Some studies indicate that the deposition of $\mathrm{Si}_{3} \mathrm{~N}_{4}$ on $\mathrm{SiO}_{2}$ results in build up of positive charge at the $\mathrm{Si}_{3} \mathrm{~N}_{4} / \mathrm{SiO}_{2}$ interface [21]. Here the possible origin of these charges in terms of the structure and composition of the considered interface is dis- 
cussed. Probably the most detailed study of the LPCVD nitride/ native oxide/silicon interfacial region has been published by Wurzbach and Grunthaner [4]. They reported that part of the native oxide still exists, while another part is converted into an oxynitride. They have also found that oxygen protrudes about $3-5 \mathrm{~nm}$ from the interface into the nitride at a low concentration, and that a thin layer $(0.8 \mathrm{~nm})$ with a significant amount of excess silicon exists about $1 \mathrm{~nm}$ away from the interface in the nitride. This excess silicon may be present in the form of $\mathrm{Si}-\mathrm{Si}, \mathrm{Si}-\mathrm{H}$ bonds or in the form of $\mathrm{Si}$ dangling bonds. A conversion of the native oxide into an oxynitride and the existence of $\mathrm{Si}-\mathrm{Si}$ bonds at the considered interface have also been observed by others $[2,22]$. Speculating about the origin of the positive interfacial charge, there are at least two options open. First of all, nitridation of $\mathrm{SiO}_{2}$ in $\mathrm{NH}_{3}$ leads to the build up of positive charge in the nitroxide (= nitrided oxide) [23]. Secondly, it has been suggested that in $\mathrm{Si}_{3} \mathrm{~N}_{4}$ the existence of positive charge is associated with $\mathrm{Si}-\mathrm{H}$ bonds $[24,25]$.

Detailed information about the interfacial composition of the oxynitride/ oxide interface is not available at the moment. However there are strong indications that the positive interface charge is present at these interfaces as well [14].

\subsection{PECVD silicon oxynitrides}

In this section some recent work in the field of plasma enhanced deposited silicon oxynitrides is briefly discussed. Special attention will be paid to those phenomena which may be important for the understanding of oxynitrides in general. Apart from recent developments in the deposition of these materials [26] these PECVD oxynitrides contain a large amount of $\mathbf{H}$ and should therefore, strictly speaking, not be considered as oxynitrides. However, it is plausible that the (hydrogen) chemistry is equal for the LPCVD and PECVD materials and the study of the plasma material may be of help for the understanding of LPCVD material.

Plasma (oxy)nitrides are mostly deposited using $\mathrm{SiH}_{4}$ as the silicon containing gas. The introduction of $\mathrm{N}$ can be performed using $\mathrm{N}_{2}$ or $\mathrm{NH}_{3}$ and oxygen is incorporated in most cases from $\mathrm{N}_{2} \mathrm{O}$. Using these input gases again the full range from nitride to oxide can be covered, albeit with the understanding that the plasma oxide may contain some $\mathrm{N}$ originating from the $\mathrm{N}_{2} \mathrm{O}$ [27]. In the plasma nitride hydrogen is bound to $\mathrm{Si}$ and $\mathrm{N}$, but depending on the deposition conditions the relative contributions of both binding states to the total $\mathrm{H}$ concentration may vary strongly, the total $\mathrm{H}$ concentration remaining the same [28]. The same is true for plasma oxynitrides: these materials may contain both $\mathrm{Si}-\mathrm{H}$ and $\mathrm{N}-\mathrm{H}$ bonds in appreciable amounts. It appeared possible to deposit these materials containing only $\mathrm{N}-\mathrm{H}$ bonds and in the oxygen-rich oxynitrides as much $\mathrm{N}$ as $\mathrm{H}$ may be incorporated [27]. The IR 


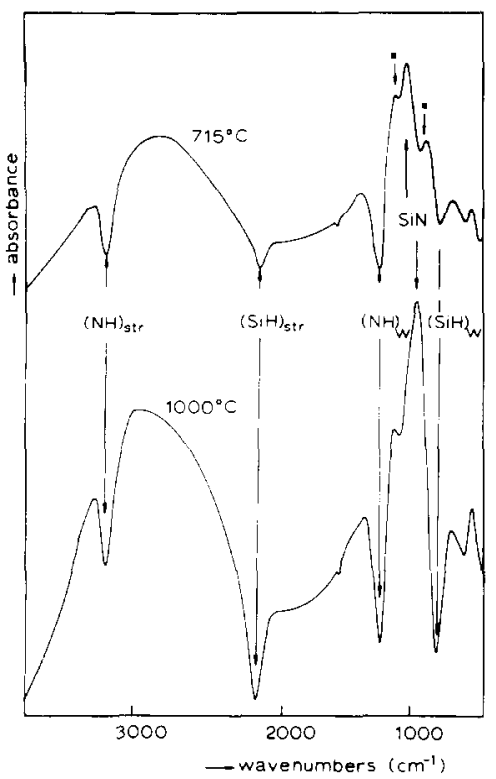

Fig. 5. Difference in infrared absorbance of an unannealed and an unannealed PECVD silicon oxynitride containing both $\mathrm{N}-\mathrm{H}$ and $\mathrm{Si}-\mathrm{H}$ bonds.

absorption frequency for both the $\mathrm{N}-\mathrm{H}$ and $\mathrm{Si}-\mathrm{H}$ stretching mode increases with increasing oxygen content of the oxynitrides [30]. In some cases also $\mathrm{O}-\mathrm{H}$ bonds were observed after deposition at large $\mathrm{N}_{2} \mathrm{O} / \mathrm{SiH}_{4}$ gas phase ratios [29].

The oxynitrides which contain hydrogen in $\mathrm{N}-\mathrm{H}$ bonds only, appeared to be heat resistant up to temperatures of $850^{\circ} \mathrm{C}$. The films which contained both $\mathrm{Si}-\mathrm{H}$ and $\mathrm{N}-\mathrm{H}$ bonds, lose a part of their hydrogen, and show cracking and shrinking already at annealing above $600^{\circ} \mathrm{C}$ [30]. Upon annealing of the latter material an increase in $\mathrm{Si}-\mathrm{N}$ bond concentrations was observed to accompany decreases in $\mathrm{Si}-\mathrm{H}$ and $\mathrm{N}-\mathrm{H}$ bond concentrations (fig. 5). These phenomena strongly suggest that the possibility of cross linking of $\mathrm{Si}$ and $\mathrm{N}$ via the reactions

$$
\begin{aligned}
\mathrm{Si}-\mathrm{H}+\mathrm{N}-\mathrm{H} & \rightarrow \mathrm{Si}-\mathrm{N}+\mathrm{H}_{2}, \\
2 \mathrm{Si}-\mathrm{H} & \rightarrow \mathrm{Si}-\mathrm{Si}+\mathrm{H}_{2},
\end{aligned}
$$

governs the $\mathrm{H}$ effusion at $T<900^{\circ} \mathrm{C}$. Consistently, no increase in ESR active centers (i.e. neutral $\mathrm{Si}$-dangling bonds) were observed after annealing the material at $T<1000^{\circ} \mathrm{C}$ although the amount of $\mathrm{Si}-\mathrm{H}$ bonds strongly decreased [31]. An increase in ESR active centers is observed when the material is annealed at temperatures above $900^{\circ} \mathrm{C}$, indicating that above this temperature single bond breaking may occur. 


\section{Synthesis}

One of the most relevant conclusions from the plasma oxynitride work for the LPCVD part is that single bond breaking of $\mathrm{Si}-\mathrm{H}$ and $\mathrm{N}-\mathrm{H}$ apparently occurs only at $T>900^{\circ} \mathrm{C}$. This implies that under the conditions of LPCVD, i.e. around $T=800^{\circ} \mathrm{C}$, the growth is accomplished via cross-linking of $2 \mathrm{Si}-\mathrm{H}$ groups and a $\mathrm{Si}-\mathrm{H}$ and $\mathrm{N}-\mathrm{H}$ group. The former results in the existence of $\mathrm{Si}-\mathrm{Si}$ bonds and the latter represents the nitride growth process. To avoid $\mathrm{Si}-\mathrm{Si}$ bonds excess $\mathrm{NH}_{3}$ in the gas phase is necessary. Cross-linking of two $\mathrm{N}-\mathrm{H}$ groups producing $\mathrm{N}_{2}$ and $\mathrm{H}_{2}$ does not result in deposition since the $\mathrm{N}_{2}$ is supposed to desorb from the surface. The operation of the cross-linking effect also explains the lack of $\mathrm{O}-\mathrm{H}$ bonds in LPCVD material. Where they occur they have probably already been formed in the gas phase, for instance via a reaction of $\mathrm{O}_{2}$ and $\mathrm{SiH}_{4}$ [18]. Note that in order to obtain hydrogen-free LPCVD nitride films at $T<1000^{\circ} \mathrm{C}$ equal amounts of $\mathrm{Si}-\mathrm{H}$ and $\mathrm{N}-\mathrm{H}$ groups must be present on the growth surface; this is not the case because the gas phase is rich in $\mathrm{NH}_{3}$. Therefore there remain more $\mathrm{N}-\mathrm{H}$ bonds than $\mathrm{Si}-\mathrm{H}$ bonds in the material, as observed in the LPCVD nitrides. Consistently, Pan and Berry [32] have measured in LPCVD nitrides an increasing $\mathrm{N}-\mathrm{H}$ concentration upon increasing the $\mathrm{NH}_{3} / \mathrm{SiH}_{2} \mathrm{Cl}_{2}$ gas phase ratio.

The introduction of oxygen on the nitride growth surface causes steric hindering and/or an increase in activation energy of the cross-linking process closely near those sites where the oxygen is inserted. This will result in an increase of the relative $\mathrm{Si}-\mathrm{H}$ and $\mathrm{N}-\mathrm{H}$ bond concentrations, whereas the growth rate will decrease. Both effects are indeed observed. In further implies that the $\mathrm{N}-\mathrm{H}$ and $\mathrm{Si}-\mathrm{H}$ bonds will be located near $\mathrm{Si}-\mathrm{O}$ bonds resulting in a shift of the IR absorption frequency to higher wavenumbers as is observed for the $\mathrm{N}-\mathrm{H}$ bonds. The increase in $\mathrm{Cl}$ concentration with increasing $\mathrm{O} /(\mathrm{O}+\mathrm{N})$ indicates that a similar kind of cross-linking involving $\mathrm{Cl}, \mathrm{N}-\mathrm{H}$ or $\mathrm{Si}-\mathrm{H}$ may also be operative.

At the onset of nitride deposition the native oxide is partly converted into an oxynitride. Nitridation of $\mathrm{SiO}_{2}$ takes place via exchange of oxygen and nitrogen [33]. This implies that $\mathrm{OH}_{x}$ is liberated during the initial stage of growth. The liberated oxygen species may react with near surface $\mathrm{SiH}_{2} \mathrm{Cl}_{2}$ species and again be incorporated in the nitride. So a small $\mathrm{O}$ concentration in the interface region extending in the nitride in a NOS structure is expected and has also been observed [4]. According to the foregoing the oxygen incorporation in the nitride results in an increase in $\mathrm{Si}-\mathrm{H}$ bond concentration. The presence of $\mathrm{Si}-\mathrm{H}$ in the interfacial region has also been suggested on the basis of electrical measurements (see section 3.1). In fact, small hydrogen pile ups have been observed in $H$ profiling measurements, but the significancy of the occurrence was doubted [8,34], also because the $H$ appeared not to remain with sufficient stability in the insulator films to allow for good statistics during profiling with high energy ion beams. 
The onset of single bond breaking of $\mathrm{Si}-\mathrm{H}$ appears at higher temperatures than the deposition temperature, as argued above. This indicates that $\mathrm{Si}-\mathrm{Si}$ bonds are more readily formed than $\mathrm{Si}$ dangling bonds. One prediction of the model would be that the concentration of the $\mathrm{Si}-\mathrm{Si}$ bonds in the material increases with increasing oxygen content. This is because a surface $\mathrm{Si}-\mathrm{H}$ bond has a larger probability to react with an impinging $\mathrm{SiH}_{2} \mathrm{Cl}_{2}$ fragment if the $\mathrm{NH}_{3}$ gas phase concentration is lowered to the advantage of the $\mathrm{N}_{2} \mathrm{O}$ concentration. However, this effect may be obscured by a rupture of these $\mathrm{Si}-\mathrm{Si}$ bonds by oxygen to form a $\mathrm{Si}-\mathrm{O}-\mathrm{Si}$ group. The possibility for this post-deposition oxidation by $\mathrm{N}_{2} \mathrm{O}$ has been proven by Keim [35]. As a net result the $\mathrm{Si}-\mathrm{Si}$ bond concentration may be reduced at increasing oxygen uptake.

\section{Acknowledgments}

The author wishes to thank his collaborators in the ESPRIT project 369 Werner van der Weg, Jos Oude Elferink (Utrecht University), Herman Maes, Roger De Keersmaecker, Johan Remmerie, Marc Heyns (IMEC, Leuven), Ton Kuiper (Philips Research Labs), Jean-Luc Ledys (MHS, Nantes), Alan Atkinson and John Riviere (AERE, Harwell) for their contributions to this work and for the stimulating atmosphere within the project. The EC is gratefully acknowledged for the financial support. The involvement of Barry O'Shea in the guidance of the project is appreciated. Further Christian Denisse is acknowledged for his contribution to the plasma part of the paper and for many useful discussions.

\section{References}

[1] R. Hezel and N. Lieske, J. Appl. Phys. 51 (1980) 2566.

[2] A. van Oostrom, L. Augustus, F.H.P.M. Habraken and A.E.T. Kuiper, J. Vacuum Sci. Technol. 20 (1982) 953.

[3] J. Remmerie, Thesis, University of Leuven (1987) ch. I.

[4] J.A. Wurzbach and F.J. Grunthaner, J. Electrochem. Soc. 130 (1983) 691.

[5] H.J. Stein, S.T. Picraux and P.H. Holloway, IEEE Trans. Electron Devices ED-25 (1978) 1008.

[6] F.H.P.M. Habraken, A.E.T, Kuiper, A. van Oostrom, Y. Tamminga and J.B. Theeten, J. Appl. Phys. 53 (1982) 404.

[7] Y. Tamminga, M.F.C. Willemsen, F.H.P.M. Habraken and A.E.T. Kuiper, Nucl. Instr. Methods 200 (1982) 499.

[8] F.H.P.M. Habraken, R.H.G. Tijhaar, W.F. van der Weg, A.E.T. Kuiper and M.F.C. Willemsen, J. Appl. Phys. 59 (1986) 447.

[9] P.S. Peercy and H.J. Stein, in: Proc. Symp. on Silicon Nitride Thin Insulating Films, Electrochemical Society, San Francisco, CA, 1983, ECS Vol. 83-8, Eds. V. Kapoor and H.J. Stein (Electrochemical Society, 1983) p. 3. 
[10] H.J. Stein and H.A.R. Wegener, J. Electrochem. Soc. 124 (1977) 908.

[11] W.A. Lanford and M.J. Rand, J. Appl. Phys. 49 (1978) 2473.

[12] J. Remmerie, Thesis, University of Leuven (1987) ch. II.

[13] P. Pan, J. Abernathey and C. Schaefer, J. Electron. Mater. 14 (1985) 617.

[14] J. Remmerie. Thesis, University of Leuven (1987) ch. IV.

[15] A.E.T. Kuiper, S.W. Koo, F.H.P.M. Habraken and Y. Tamminga, J. Vacuum Sci. Technol. B1 (1983) 62 .

[16] A.E.T. Kuiper, F.H.P.M. Habraken, A. van Oostrom and Y. Tamminga, Philips J. Res. 38 (1983) 1.

[17] B. Verstegen, F.H.P.M. Habraken, W.F. van der Weg, J. Holsbrink and J. Snijder, J. Appl. Phys. 57 (1985) 2766.

[18] P.S. Peercy, H.J. Stein, B.L. Doyle and V.A. Wells, in: Proc. 7th Intern. Conf. on Chemical Vapor Deposition, Los Angeles, ECS Vol. 79-3, Eds. T.O. Sedgwick and H. Lydtin (Electrochemical Society, Pennington, NJ, 1979).

[19] M. Nishijima, K. Edamoto, Y. Kubota. S. Tanaka and M. Onchi, J. Chem. Phys. 84 (1986) 6458.

[20] J.B. Oude Elferink, U.A. van der Heide, W.M. Arnold Bik, F.H.P.M. Habraken and W.F. van der Weg, Appl. Surface Sci. 30 (1987) 197.

[21] K. Rajkanan and J.S. Multani, J. Electrochem. Soc. 130 (1983) 1152.

[22] R. Hezel and N. Lieske, in: Proc. on Insulating Films on Semiconductors, Durham. 1979. Eds. G.G. Roberts and M.J. Morant [Inst. Phys. Conf. Ser. 450 (1979) 206].

[23] G.A. Ruggles and J.R. Monkowski, J. Electrochem. Soc. 133 (1986) 787.

[24] H.J. Stein, J. Electrochem. Soc. 129 (1982) 1786.

[25] H.E. Maes and J. Remmerie, in: Proc. Symp. on Silicon Nitride '[hın Insulating Films, Electrochemical Society, San Francisco, CA, 1983, ECS Vol. 83-8, Eds. V. Kapoor and H.J. Stein (Electrochemical Society, 1983) p. 73.

[26] G. Lucovsky, P.D. Richard, D.V. Tsu, S.Y. Lin and R.J. Markunas, J. Vacuum Sci. Technol. A4 (1986) 681.

[27] C.M.M. Denisse, K.Z. Troost, J.B. Oude Elferink, F.H.P.M. Habraken, W.F, van der Weg and M. Hendriks, J. Appl. Phys. 60 (1986) 2536.

[28] W.A.P. Claassen, W.G.J.N. Valkenburg, F.H.P.M. Habraken and Y. Tamminga, J. Electrochem. Soc. 130 (1983) 2420.

[29] Y. Cros and J.C. Rostaing, in: Proc. European MRS Spring Meeting, Strasbourg. 1986. Ed. G.G. Bentini (Les Editions de Physique, Les Ulis, 1986) p. 77.

[30] C.M.M. Denisse, K.Z. Troost, F.H.P.M. Habraken, W.F. van der Weg and M. Hendriks, J. Appl. Phys. 60 (1986) 2543.

[31] C.M.M. Denisse, J.F.M. Janssen, F.H.P.M. Habraken, W.F. van der Weg and E.G.P. Schuivens, J. Appl. Phys., to be published.

[32] P. Pan and W. Berry, J. Electrochem. Soc. 132 (1985) 3001.

[33] F.H.P.M. Habraken, A.E.T. Kuiper, Y. Tamminga and J.B. Theeten, J. Appl. Phys. 53 (1982) 6996.

[34] F.H.P.M. Habraken, J.B. Oude Elferink, P. Eppenga and A.E.T. Kuiper, in: Proc. In-Depth Review of the Nuclear Accelerator Impact in the Interdisciplinary Field, Padua, 1984, Eds. P. Mazzoldi and G. Moschini (Laboratori Nazionali di Legnaro, Padua, ltaly) p. 50.

[35] E.G. Keim, Thesis, University of Twente (1984). 